\title{
Obituary
}

\section{Professor Sudhakar Ratanlal Joharapurkar}

Brij R Singh, Arvind Bhake ${ }^{1}$, Amit Agarwal ${ }^{2}$

Departments of Radiology, ${ }^{1}$ Pathology, ${ }^{2}$ Neurosurgery, Datta Meghe Institute of Medical Sciences, Sawangi (Meghe), Wardha (India)

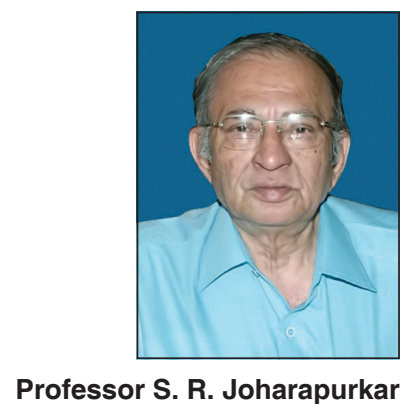

$(16 / 02 / 1940-13 / 11 / 2009)$

Professor Sudhakar Ratanlal Joharapurkar, popularly known as SRJ amongst his friends and academicians across India, has been a philosopher to many, surgeon for more and academician for most.

Dr. Sudhakar Joharapurkar was born in a small town of Amaravati district in the state of Maharashtra (India). As a young medical student, he joined the Government Medical College, Nagpur, Maharashtra, and completed post graduation from the same institute in the discipline of Surgery. Known for his studious and helpful nature as a student, he grew up to be a workaholic and soon a skillful surgeon and the most loved teacher of surgery. He spent a quarter of a century at the Government Medical College, Nagpur and worked in all capacities. He had a unique style of teaching surgery and the astuteness of an academician while guiding the postgraduates during their training at Masters of Surgery. Dr. Joharapurkar was a famous figure in gatherings of surgeons at national and regional conferences; he continued medical education programs and organized workshops on varied surgical aspects.

Dr. Joharapurkar stood tall. He had to his credit path breaking publications on many topics and also a few books for medical students to simplify the subject of surgery. His administration left an indelible mark on those who watched him as the Director of Datta Meghe IMS (Deemed University), Sawangi (M), Wardha, Maharashtra (India). His innovative approach has transformed this place from a small medical institute to a large multidisciplinary center of medical academics and patient care services. His sudden and sad demise has left all his students, acquaintances, colleagues and friends in sorrow.

The Editorial Board of Journal of Neurosciences in Rural Practice pays a tribute to this towering personality, who was founder, Executive Editor and steered this journal through the initial difficult phases. We pray to almighty - may his soul rest in peace and his life continue to inspire us.

Address for correspondence:

Dr. Amit Agrawal, Department of Neurosurgery, Datta Meghe Institute of Medical Sciences, Sawangi (Meghe), Wardha- 442 004, Maharashtra, India. E-mail: dramitagrawal@gmail.com 